\title{
Discussion on the Application of Class Group Psychological Guidance in Cultivating Tuition-free Medical Students' "Empathy"
}

\author{
Xi Gong \\ Department of Psychology \\ Gannan Medical University \\ Rural Medical Education Research Center \\ Gannan Medical University \\ Ganzhou, China 341000
}

\author{
Wen $\mathrm{Hu}$ \\ Department of Psychology \\ Gannan Medical University \\ Ganzhou, China 341000
}

\begin{abstract}
As grassroots medical workers, tuition-free medical students who hold "empathy" may do good to form a well going doctor-patient relationship. Theoretical researches and practices show that class group psychological guidance is an effective way to carry out the "empathy" work. This article conducts discussions on the group psychological guidance from listening training, observation technical training, emotional understanding training and expression training so as to provide the tuition-free medical students references for training of "empathy" abilities.
\end{abstract}

Keywords-class group psychological guidance; tuition-free medical students; empathy

\section{INTRODUCTION}

On Aug 20, 2016, President Xi Jinping made an important speech at the National Sanitation and Health Conference, pointing out that "medical treatment shall be focused on grassroots and prevention first". In order to strengthen the construction of grassroots medical and health personnel teams, Gannan Medical University recruited tuition-free medical students early in 2010, hoping to cultivate quality and generalpurpose medical talents who are agreeing to work, capable of work and willing to work at grassroots medical instructions through tuition free training and targeted employment. At present, the grassroots medical services are in a serious environment, and the relationship between doctors and patients is tense, there are many reasons which have caused such situation, in addition to the medical technologies which are far to meet what the people need, the poor medical professional quality of medical workers at grassroots is also a key factor. Professional quality can be shown in different dimensions, the empathy is one part of it. A survey made on the empathies of a large number of doctors show the average empathy of doctors is kept at a low level, during the communication between doctors and patients, it is very difficult to use advanced empathy to respond to the medical process, deal with doctorpatient relationship, which otherwise, often causes doctorpatient conflicts. Doctors having empathy quality at grassroots can care about patients at heart and stand on the side of patients and their family members, listening to the reasonable appeals of patients and showing sincere understanding and support to the patients. As such, it will do good to create a mutually beneficial and harmonious relation between doctors and patients and promote the well going of medical work. Therefore, the tuition-free medical students, as medical workers at grassroots, are required to actively develop and improve the empathy capabilities while getting professional knowledge and skills, which is a significant teaching aim for higher medical education to accomplish.

The class group psychological guidance has unique advantages, which in recent years has been accepted by scholars and teachers. The recipients that the class group psychological guidance aims at are the whole class of students, and the advantages such as class culture and study groups can be fully used for carrying out the psychological guidance work. Compared to professional group guidance, the class group guidance needs lower professional requirements, and the teaches having no psychological background can immediately grasp the strategy and skills for group guidance and can execute the operation in class after receiving a series of training. The empathy belongs to a mental activity, and the cultivation of the abilities can be done at any time, anywhere and among any relations. So tuition-free medical students may continuously exercise the empathy skills in daily life. Besides, teachers can also discover and create chances for study in teaching or class activities in support of the student for exercising the empathy.

During the class group guidance, what are the projects to exercise the empathy? If the projects work well, we can build a systematic cognitive behavior study platform for the tuition free medical students, where the students will get relevant knowledge and skills to enhance the "empathy" quality. Based on this point, this article attempts to set reasonable and effective empathy guidance contents via the class group psychological guidance technique so as to provide suggestions for the empathy group psychological guidance. 


\section{CONCEPT OF EMPATHY}

The empathy, also called trans-positional consideration, refers to an understanding and entering into another's feelings and passing the understanding to the other. Spoken concretely, think about problems just as if you were the persons concerned, make use of listening to touch and understand others' feelings, thought and emption, and use reasonable and constructive languages to express what you feel, want to say to and share with others.

In the 1980s, the concept of "empathy" was introduced to the medical field. In the opinion of La Monica, the "empathy" means that doctors can be parts of patients' world, sharing the feeling with the patients, of which, the doctors shall accurately touch and understand the feeling of patients, showing patients what they feel and getting what the patients feel to doctors. Carl Ransom Rogers thought that the empathy is what doctors should do, that is, doctors should understand what the patients are have in body and mind, understand the paints that patients bear.

As far as the doctor-patient relationship, the doctors shall have empathies including a wide range of abilities such as the ability to make trans-positional consideration and to feel and think as if they were the patients, really understanding that the patients need psychologically; able to understand and accept what the patients express emotionally and how it is done; able to effectively pass how they value and understand the patients accurately to the patients; able to calmly express what they feel, think and express, showing attitudes to meet the reasonable appeals of the patients.

\section{CONTENTS OF THE EMPATHY CLASS GROUP PSYCHOLOGICAL GUIDANCE}

\section{A. The Aim of Class Group Psychological Guidance}

1. Help tuition-free medical students to master basic skills of empathy;

2. Aid tuition-free medical students to apply the empathy technique to deal with interpersonal conflicts and develop a good interpersonal relation;

3. Set clinical cases or other modes to train the students' empathy in practice and scene transfer

\section{B. The Core of Class Group Psychological Guidance}

1) "Empathy" training model: In the 1980s, psychologist Feshbach created a three-dimensional training model aiming at the empathy training. According to his opinions, helpers can be trained in cognition, emotion and behavior, main contents include identification of emotional hint, empathy and emotional response. In the opinion of this author, the group guidance on the empathy for the medical students may borrow the three-dimensional training model, and conduct orderly training in cognition, emotion and behavior.

Cognition: refers to an ability of understanding and thought. Multiple modes such as listening training, observation skill training and so on can be used to train the medical students in thought, feeling, emotional perception, awareness and judgment on patients.

Emotion: refers to an ability of emotional expression. The emotional perception training can be used to train the medical students in understanding and feeling of emption to patients.

Behavior: refers to an ability of behavioral expression. Non-language and language expressions can be used to train the medical students in accurately and reasonably expressing what patients think and feel in the contents and emotions.

2) Contents of empathy training: The empathy training is a systematic and orderly group guidance course, where there are many training contents to complete, of which, core contents are selected by this author for analysis.

a) Listening training: One of the important ways for doctors to access to patients' cognitive and emotional information is to listen. Many times, we get used to saying but ignoring listening, the mode of saying more and listening less may cause potential risks of doctor- patient conflicts. During the communication between doctors and patients, before showing ideas and attitudes, the doctors are suggested to spend a few times listening carefully so as to fully understand and grasp what the patients think and touch what the patients feel before targeted communication. The listening may help the patients feel the doctors' understanding, care and support to them, and also to enable the doctors really understand what the patients think and feel in heart.

During the group psychological guidance, the first step for the empathy training is listening, which can exercised trough a lot of scene practices so as to improve the perception and judgment of medical students to the languages and emotional expression of others. For example, set a clinical situation for role play, the students will talk with "patients" and then express that they have listened from the "patients", which will be evaluated by tutors, patients and other members and finally instructed.

b) Observation skill training: During the interpersonal communications, there are many ways for delivering information, language is one of them, there are a lot of information which are delivered via non-language modes, besides, the non-language modes often deliver more and effective information for references. Especially for the doctorpatient relationship, the communication between doctors and patients, in addition to speaking, can be achieved many times through non-language modes such as sights, eyes, gestures, body, expression, tone and so on. In foreign countries, medical colleges and universities attach great importance to the sensitivity training of medical students on the non-language modes, which however, is still poor in China.

During the group psychological guidance, we should carry out the empathy training especially the observation skill training. Pictures, videos, role-playing and so on can be adopted to help the students learn to effectively identify patient's non-language behaviors so as to more objective and accurate to identify what the patients want and show. Besides, based on the skills, the students may also express their acceptance, respects and support to the patients via active non- 
language behaviors so as to get trusted and cooperated by patients and create a good medical relationship.

c) Emotional feeling and comprehension training: One of the key goals of medical education is to alleviate the pain of patients. But the status quo turns out that doctors are poor in feeling and dealing with the pains of patients. What doctors should do is not simple diagnosis and treatment, for them, a very important task is to show their understanding as if they were the patients, master and accept what the patients show in emotion, and take active measures for intervention so as to help the patients well treat their emotions.

In the group of psychological counseling in the same mind training, to train free medical students to perceive, understand and actively deal with the patient's emotional feelings. In this session, you can train through the role-playing activities. For example, the establishment of clinical situation, so that free medical students to receive emotional or emotional pain "patients", "patients" to the medical students to tell their own symptoms and feelings, medical students with "empathy" dialogue, given Feedback, to help "patient" emotional adjustment. You can also use role conversion activities to train. For example, set a doctor-patient situation, where the medical students act as "patients", showing "doctors" their symptoms and pains, yet the "doctors" are less responding. Through the role exchanging, the medical students may truly feel what the patients feel and think what the patients think. Through a series of exercises, the emotional awareness and understanding of medical students will be deepened to strengthen their abilities to deal with in emotion.

d) Accurate expression training: The "Empathy" not only requires the doctors to show their understanding and empathy, but also to express what they feel and think by ways that are understandable and acceptable for patients. If it improperly expressed, it may deliver wrong information, doing bad to the formation of sound doctor-patient relationship.

During the group psychological guidance, the empathy training is carried out where it aims to train the students' abilities in expression, when training, the students after hearing what the "patients" express, shall are acting actively to show not only in contents but also in emotion. Then the "patients" will feed back to what the doctors have expressed, indicating the languages and gestures that they feel bad. Through the exercises, the students may get active ways for expression to which patients don't say no or refuse.

\section{CONCLUSION}

In conclusion, a good empathy will do good to improve the professional emotional quality and communication skills of medical students, which is a significant base for the medical students to build sound doctor-patient relationship at grassroots in the future. The class group psychological guidance, where three-dimensional trainings including cognition, emotion and behavior in the empathy are carried out, plays an important role in improving the students' empathy. The medical education workers should value to cultivate the students' abilities in empathy and keep continuous attempts and exploration in order to find more efficient cultivation modes and training skills in practice.

\section{REFERENCES}

[1] Cao Jinya, Wei Jing, Shi Lili, et al, Empathy and Difficulty in Medical Activities: The Roles of Balint Work to Promote the Empathy [J] Medicine \& Philosophy, 2015, 36(4B): 4 7.

[2] Wang Xiaocan, Geng Xiaoping, Wang Weili, et al, Strategies to Optimize Doctor-Patient Relationship: Doctor-Patient Interaction and Empathy Led by Medical Workers [J] Medicine \& Philosophy, Philosophy, 2016, 37(1B): 94-Cover III. 